\title{
Article
}

\section{Cost-effective prescribing and health economics}

\author{
Broadhead, Ruth
}

Available at http://clok.uclan.ac.uk/37438/

Broadhead, Ruth (2021) Cost-effective prescribing and health economics. Journal of Prescribing Practice, 3 (4). ISSN 2631-8385

It is advisable to refer to the publisher's version if you intend to cite from the work.

For more information about UCLan's research in this area go to http://www.uclan.ac.uk/researchgroups/ and search for <name of research Group>.

For information about Research generally at UCLan please go to http://www.uclan.ac.uk/research/

All outputs in CLoK are protected by Intellectual Property Rights law, including Copyright law. Copyright, IPR and Moral Rights for the works on this site are retained by the individual authors and/or other copyright owners. Terms and conditions for use of this material are defined in the policies page.

\section{CLoK}

Central Lancashire online Knowledge www.clok.uclan.ac.uk 


\section{Journal of Prescribing Practice}

\section{Calculation Skills - Cost-effective prescribing \& health economics}

\section{Ruth Broadhead 28.03.21}

Developing an awareness of cost is a fundamental feature of prescribing practice and the Royal Pharmaceutical Society (RPS) (2016) includes this principle within the 'Consultation domain' as a definitive competency for all prescribers. Within the framework, (Competency 2: Consider the options), sub-competency 2.8 states that the prescriber: 'Stays up-to-date in own area of practice and applies the principles of evidence-based practice, including clinical and cost-effectiveness'. The General Pharmaceutical Council (GPhC) (2019) stipulate that pharmacist independent prescribers should attain minimum prescribing standards against specific learning outcomes. The 'professionalism domain', learning outcome 13, within the GPhC document requires that pharmacists "apply an understanding of health economics when making prescribing decisions" (GPhC, 2019, pg. 8). Similarly, the Nursing \& Midwifery Council (2018) and the Health \& Care Professions Council (2019) alert their prescribing registrants to prescribe cost-effectively using the RPS competency framework.

The National Prescribing Centre (NPC) (1999) devised the mnemonic EASE to alert the prescriber to consider that prescribed medications should be Effective, Appropriate, Safe and cost-Effective. In terms of cost, the use of EASE during the prescribing process prompts the prescriber to consider whether their prescribing decisions take account of budgetary constraints and health economics. Haycox (2009) defines health economics as a valuable tool for improving clinical decisions whereby the prescriber identifies alternative, cost-based options for their patients in respect of drug choice and maps this against clinical efficacy, available resources and patient outcomes.

Cost-effective prescribing is not always about prescribing the cheapest option for patients, but more concerned with maximising drug efficacy and medicines optimisation (Nuttall, 2020). There are finite resources available to prescribers within the NHS and the lower cost product may not be the most appropriate choice for the patient (King's Fund, 2018). It is stated in this report that the prescribing of cheaper, generic drugs should take precedence over the more expensive branded alternatives, and as an example, prescribers should consider 'biosimilars' for some long-term conditions. Biosimilars resemble generic drugs, but these medicines generally cost less than the original biological medicine, but with equal safety and efficacy (NHS UK, 2020). As 'cost-aware' prescribers, therefore, a balance needs to be reached between clinical efficacy and cost-effectiveness when making clinical decisions about medications that are to be prescribed against NHS budgets.

The following drug calculations offer the opportunity for you to consider cost-effective prescribing decisions.

\section{Question 1}

Mrs Smith has chronic venous leg ulcers. She has been prescribed Dressing $X$ for the last 60 days with good overall clinical efficacy. The wound dimensions were originally $6 \mathrm{~cm} \times 8 \mathrm{~cm}$ and Dressing $X$ was prescribed in $10 \mathrm{~cm} \times 10 \mathrm{~cm}$ pieces to be applied daily. The cost of $10 \mathrm{~cm}$ $x 10 \mathrm{~cm}$ dressings is $£ 26.22$ per box of 20 . Mrs. Smith's leg ulcer is healing well, and the wound dimensions are now $2 \mathrm{~cm} \times 4 \mathrm{~cm}$. Dressing $X$ is also available in $5 \mathrm{~cm} \times 5 \mathrm{~cm}$ and cost $£ 18.48$ per box of 20 . Assuming that the $5 \mathrm{~cm} \times 5 \mathrm{~cm}$ are prescribed for the next 60 days, using one dressing daily, what is the overall cost saving?

\section{Question 2}

Jane has rheumatoid arthritis. A clinical decision has been made to commence biological treatment. Biological $A$ is prescribed at $125 \mathrm{mg} / \mathrm{ml} \mathrm{S} / \mathrm{C}$ injection once weekly for 4 weeks. 
The cost is $£ 1,209.60$ for 4 pre-filled syringes. However, Biosimilar $B$ is considered as a cost-efficient alternative and is available in vials of $500 \mathrm{mg} / 50 \mathrm{ml}$ for IV infusion. Each vial costs $£ 571.67$. The dose for Biosimilar B is $500 \mathrm{mg}$ every 2 weeks. Over a 4 -week treatment regime:

a. What is the weekly cost for Biologic A?

b. What is the weekly cost for Biosimilar $B$ ?

Assuming Biosimilar $B$ is prescribed for Jane:

c. What is the total cost for 4 weeks?

d. What is the saving made to the NHS over the 4 weeks by prescribing the Biosimilar $B$ rather than Biological $A$ ?

\section{Question 3}

Daniel has been diagnosed with severe hypertension and Drug $Y$ has been prescribed once daily at a cost of $£ 44.20$ for 28 tablets. You prescribe Drug $Y$ for 56 days at which point, you will review the patient.

a. What is the cost of Drug $Y$ for the 56 days?

b. How much would this treatment cost for 1 year (assume one month $=28$ days) ?

Daniel returns after 2 weeks having developed an intolerance to Drug Y.

c. How many tablets will remain unused?

d. What is the cost of this loss to the NHS?

\section{Question 4}

For optimal medicines management, you undertake a review of Ethel's medication prior to discharge following successful admission for a total hip replacement. There are 4 drugs that are considered suitable for deprescribing. These are:

i. Drug 1 is currently prescribed on repeat by her GP and is no longer clinically required. The drug is currently prescribed at $100 \mathrm{mg}$ tablets three times a day and costs 20 p per dose. Over a year (365 days), how much will be saved by the NHS once this drug is discontinued?

ii. Drug 2 is taken twice daily by Ethel and is deprescribed prior to discharge from hospital. This has been replaced by Drug 3 to be taken once daily. Drug 2 costs $£ 8.90$ per dose and Drug 3 costs $£ 8.90$ per dose. What is the total saving per day by deprescribing Drug 2?

iii. Dressing 1 is deprescribed and replaced by the cheaper generic Dressing 2 for postop wound care. The cost difference is $£ 2.40$ per dressing. Over 7 days assuming one dressing is used per day, how much will be saved by prescribing generically?

iv. Ethel developed a post-op hospital-acquired wound infection and was prescribed intravenous antibiotics for 7 days. These are deprescribed at a cost-saving of £94.00 per day. Oral antibiotics are prescribed on Ethel's discharge to be taken at $1 \mathrm{~g}$ every 6 hours for 5 days. The capsules are $250 \mathrm{mg}$ strength and cost $£ 1.25$ per capsule.

a. How much will a 5-day course of oral antibiotics cost?

b. Over the in-patient stay plus the course of antibiotics prescribed to Ethel on discharge, what has been the overall cost of antibiotics for this hospital-acquired wound infection? 


\section{References}

General Pharmaceutical Society (2019). Standards for the education and training of pharmacist independent prescribers. London. GPhC.

Haycox, A. (2009). What is health economics? Available at: www.whatisseries.co.uk Accessed 28.03.21

Health \& Care Professions Council (2019). Standards for prescribing. London. HCPC.

King's Fund (2018). The rising cost of medicines to the NHS. What's the story? Available at: https://www.kingsfund.org.uk/publications/rising-cost-medicines-nhs Accessed 28.03.21

National Health Service UK (2020). Biological and biosimilar medicines (biosimilars)

https://www.nhs.uk/conditions/biological-and-biosimilar-medicines/ Accessed 28.03.21

National Prescribing Centre (1999). Signposts for prescribing nurses - general principles of good prescribing. Prescribing Nurse Bulletin.

Nursing \& Midwifery Council (2018). Standards for prescribing programmes. London. NMC

Nuttall, D. (2020) Prescribing in Context. In Nuttall, D. \& Rutt-Howard, J. (Eds) (2020) The textbook of Non-Medical Prescribing. Chichester. Wiley Blackwell.

Royal Pharmaceutical Society (2016) A competency framework for all prescribers. Available at:

https://www.rpharms.com/Portals/0/RPS\%20document\%20library/Open\%20access/Professi onal\%20standards/Prescribing\%20competency\%20framework/prescribing-competencyframework.pdf Accessed 28.03.21 


\section{Answers}

Question 1

$£ 23.22$

Question 2
a. $£ 302.40$
b. $£ 285.83$
c. $\{1,143.34$
d. $\$ 66.26$

Question 3
a. $£ 88.40$
b. $£ 530.40$
c. 42 tablets
d. $\quad \mathbf{2 6 6 . 3 0}$

Question 4
i. $£ 219.00$
ii. $£ 8.90$
iii. $£ 16.80$
iv. $a . £ 100$ b. $£ 758$ 